Brit. J. prev. soc. Med. (1976), 30, 158-162

\title{
The relationship between blood pressure and biochemical risk factors in a general population
}

\author{
C. J. BULPITT, CHARLES HODES, AND M. G. EVERITT \\ Chronic Disease Control Study Unit; Department of Community Health, London School of Hygiene and Tropical Medicine \\ and the Theobald Centre, Boreham Wood
}

\begin{abstract}
Bulpitt, C. J., Hodes, C., and Everitt, M. G. (1976). British Journal of Preventive and Social Medicine, 30, 158-162. The relationship between blood pressure and biochemical risk factors in a general population. The relationship between blood pressure, ponderal index, sex, blood glucose, haemoglobin, serum uric acid, calcium, cholesterol and creatinine, and albumin has been examined in 698 subjects aged between 44 and 49 years from the register of a group general practice. Sixty per cent of the variation in systolic pressure could be explained by statistically significant associations with diastolic pressure, sex, blood glucose, serum calcium, and cholesterol. The diastolic blood pressure (not corrected for systolic pressure) was significantly related only to ponderal index, haemoglobin in men, and cholesterol in women. Pulse pressure was also positively related to the risk factors blood glucose, serum cholesterol, and calcium. The possibility is discussed that one or more of these variables reduce aortic compliance and that the serum calcium contributes to this end. Diastolic, but not systolic pressure, had a prime association with relative weight, obesity being only basically associated with an increase in diastolic pressure.
\end{abstract}

Both systolic and diastolic pressure are good predictors of subsequent mortality and morbidity (Kannel and Dawber, 1974). Diastolic blood pressure is more dependent on peripheral resistance than systolic pressure and the systolic pressure is determined to a larger extent by the compliance of the aorta and large arteries. A raised systolic pressure not only predicts subsequent disease but itself results from vascular damage which has already occurred, the compliance of the aorta being reduced by atherosclerotic disease. On the other hand, peripheral resistance arises mainly in the smaller arteries and arterioles and would be little affected by this condition. It must be noted that diastolic pressure is closely correlated with systolic pressure and factors that increase diastolic pressure may thereby increase systolic pressure.

This paper examines the relationship in a general population between systolic and diastolic blood pressure, a weight-height index and biochemical results, some of which are known to be risk factors for atherosclerotic disease. Also assessed are the factors influencing mean blood pressure, pulse pressure, and systolic pressure adjusted for diastoliō pressure. The analyses are intended to identify risk factors affecting systolic or diastolic pressure alone and which may operate by reducing aortic compliance or raising peripheral resistance.

\section{METHODS}

\section{Population STUdied}

The subjects studied were taken from 16000 patients on the list of a group practice near London, $\frac{3}{3}$ covering mainly an urban area. The middle-aged subjects were screened for hypertension and others abnormalities as previously described (Hodes, 1968a) The subjects were included in a computer file (Hodes, 1968b) and letters were sent to those aged between 44 and 49 years inviting them to attend for screening examination. Altogether 357 men and 341 womene were examined in this age group. The response ratew to two invitations was $56 \%$. At the screening clinic height and weight were measured and the sitting blood pressure was taken after 5 minutes' rest using a standard mercury sphygmomanometer, always by 
the same trained nurse. The diastolic pressure was taken as the point of muffling of sound. An $18 \mathrm{ml}$ blood sample was taken for serum creatinine, albumin, cholesterol, uric acid, and calcium estimation together with $2.5 \mathrm{ml}$ blood in fluoride oxalate bottles for haemoglobin and blood sugar determination.

\section{Biochemical Methods}

All measurements were made in the Chemical Pathology Department of the Group Laboratory, Barnet General Hospital (Head of Department, Dr Peter A. Clark).

The serum samples were separated and stored in a deep freeze; haemoglobin and glucose estimations were made within 24 hours of receipt. Albumin, calcium, creatinine, glucose, and uric acid estimations were performed by the current standard method on a Technicon auto-analyser I and cholesterol by the method of Watson (1960). Most of the haemoglobin estimations were measured by an Instrumentation Laboratories automatic haemoglobinometer.

\section{Statistical Methods}

The biochemical variables, systolic and diastolic blood pressure, age, weight, and height were tested for normality. Each variable was approximately normally distributed with the exception of serum creatinine, which was converted logarithmically to the base 10, and was then normally distributed.

A ponderal index was calculated as weight in pounds divided by the square of height in inches (Khosla and Lowe, 1967). The pulse pressure was calculated as the difference between systolic and diastolic blood pressure and the mean pressure as the diastolic blood pressure plus one-third of the pulse pressure.

The relationship between blood pressure in $\mathrm{mmHg}$ and the biochemical and other variables was assessed using multiple regression techniques. Individually, systolic, diastolic, mean, and pulse pressures were regressed on sex $(1=$ male, $2=$ female), age in years, serum uric acid in $\mathrm{mg} / 100 \mathrm{ml}$, log serum creatinine in $\log \mathrm{mg} / 100 \mathrm{ml}$, serum calcium in $\mathrm{mg} / 100 \mathrm{ml}$, serum cholesterol in $\mathrm{mg} / 100 \mathrm{ml}$, serum albumin in $\mathrm{g} / 100 \mathrm{ml}$, blood haemoglobin in $\mathrm{g} / 100 \mathrm{ml}$, blood glucose in $\mathrm{mg} / 100 \mathrm{ml}$, height in inches, weight in lbs, and ponderal index. In one regression, systolic blood pressure was in addition regressed on diastolic blood pressure.

Certain variables had not been determined for all the subjects. The initial regression was performed for all patients with a complete set of data. Variables not reaching the $5 \%$ significance level were eliminated from the regression, and the final equations used only 'significant' variables and included all subjects in whom these final variables had been determined.

The relationship between both haemoglobin and cholesterol and the diastolic blood pressure were not the same in the two sexes, and therefore (sex $\times$ haemoglobin) and (sex $\times$ cholesterol) interaction terms were included in the analysis.

\section{RESUltS}

Table I gives the number of subjects involved, the mean value, standard deviation, and the range of each measurement considered. Table II compares the average blood pressure results for both sexes. The average systolic pressure and mean pulse pressure were both greater in women.

Table III gives the final multiple regression equations for systolic, diastolic, mean, and pulse pressure. Listed are the significant $(P<0.05)$ regression coefficients, the constant, the multiple correlation coefficient (R), and the number of subjects contributing to the equation (n).

The equation given for systolic blood pressure, excluding diastolic pressure, was as follows:

Systolic blood pressure $=$

$$
\begin{aligned}
& 30 \cdot 793+1120 \cdot 16 \mathrm{Pon}+0.190 \mathrm{Glu}+ \\
& 0.052 \mathrm{Chl}+3 \cdot 709 \mathrm{Cal}+3 \cdot 773 \mathrm{Sex}
\end{aligned}
$$

and explained $13 \cdot 5 \%$ of the variation. The regression coefficients for ponderal index and blood glucose were highly significant $(P<0.001)$. Those for serum cholesterol ( $P<0.01$ ), and sex and calcium $(P<0.05)$ were also significant. There was no evidence that creatinine should be included in the equation; age, haemoglobin, serum uric acid, and serum albumin did not reach the $5 \%$ level of significance.

The regression coefficients were all positive, and the greater the relative weight, blood glucose, serum calcium, and serum cholesterol, the greater was the systolic pressure.

The equation given for diastolic pressure was based on relative weight, haemoglobin, cholesterol, sex, and the (sex $\times$ haemoglobin) and (sex $\times$ cholesterol) interaction terms. This explained $12 \cdot 3 \%$ of the variation in diastolic pressure. For both sexes the diastolic pressure rose with ponderal index, but the net effect of the haemoglobin and cholesterol interaction terms gave a rise in diastolic pressure with haemoglobin only in men. Similarly, the serum cholesterol was positively related to diastolic blood pressure only in women. 
TABLE I

RANGE AND MEAN OF THE MEASUREMENTS AND THE STANDARD DEVIATION OF A SINGLE MEASUREMENT IN 69 SUBJECTS

\begin{tabular}{|c|c|c|c|c|c|}
\hline Variable & No. & Mean & $\begin{array}{l}\text { Standard } \\
\text { Deviation }\end{array}$ & $\begin{array}{l}\text { Lowest } \\
\text { Value }\end{array}$ & $\begin{array}{c}\text { Highest } \\
\text { Value }\end{array}$ \\
\hline Systolic pressure (mmHg) & 698 & $141 \cdot 4$ & $22 \cdot 46$ & 96 & 230 \\
\hline Diastolic pressure (mmHg) & 698 & $83 \cdot 8$ & $12 \cdot 28$ & 54 & 140 \\
\hline Mean pressure (mmHg) & 698 & $103 \cdot 0$ & $14 \cdot 64$ & $69 \cdot 3$ & $163 \cdot 3$ \\
\hline Pulse pressure (mmHg) & 698 & $57 \cdot 6$ & $15 \cdot 6$ & 20 & 118 \\
\hline Age (years) & 698 & $46 \cdot 8$ & $1 \cdot 50$ & 44 & $49 \cdot 9$ \\
\hline Serum uric acid $(\mathrm{mg} / 100 \mathrm{ml})$ & 663 & $5 \cdot 07$ & $1 \cdot 26$ & $1 \cdot 4$ & $8 \cdot 7$ \\
\hline Log serum creatinine $(\log \mathrm{mg} / 100 \mathrm{ml})$ & 622 & -0.0068 & $0 \cdot 103$ & $-0 \cdot 301$ & 0.602 \\
\hline Serum calcium (mg/100ml) & 666 & $9 \cdot 95$ & 0.64 & $6 \cdot 1$ & $11 \cdot 9$ \\
\hline Serum cholesterol $(\mathrm{mg} / 100 \mathrm{ml})$ & 658 & $250 \cdot 1$ & $48 \cdot 59$ & 134 & 460 \\
\hline Serum albumin $(\mathrm{g} / 100 \mathrm{ml})$ & 653 & $4 \cdot 42$ & 0.43 & $3 \cdot 1$ & $5 \cdot 6$ \\
\hline Haemoglobin $(\mathrm{g} / 100 \mathrm{ml})$ & 628 & $14 \cdot 0$ & $1 \cdot 64$ & $6 \cdot 6$ & 20 \\
\hline Blood glucose $(\mathrm{mg} / 100 \mathrm{ml})$ & 678 & $78 \cdot 18$ & $18 \cdot 06$ & 40 & 290 \\
\hline Height (in) & 665 & $65 \cdot 29$ & $3 \cdot 59$ & 56 & 75 \\
\hline Weight (lb) & 698 & $152 \cdot 9$ & $26 \cdot 14$ & 90 & 268 \\
\hline Ponderal index $\left(w t / h t^{2}\right)$ & 665 & 0.036 & 0.005 & 0.024 & 0.06 \\
\hline
\end{tabular}

TABLE II

THE AVERAGE BLOOD PRESSURE FOR THE TWO SEXES

\begin{tabular}{|c|c|c|c|}
\hline Blood Pressure & Men & Women & $\begin{array}{l}\text { Significance } \\
\text { of Difference }\end{array}$ \\
\hline Systolic (mmHg) & $138 \cdot 9$ & $144 \cdot 0$ & $P<0.01$ \\
\hline Diastolic (mmHg) & $84 \cdot 2$ & $83 \cdot 5$ & NS \\
\hline Mean (mmHg) & $102 \cdot 4$ & $103 \cdot 6$ & NS \\
\hline Pulse (mmHg) & $54 \cdot 8$ & 60.6 & $P<0.001$ \\
\hline Number & 357 & 341 & \\
\hline
\end{tabular}

TABLE III

REGRESSION OF BLOOD PRESSURE ON NINE INDEPENDENT VARIABLES

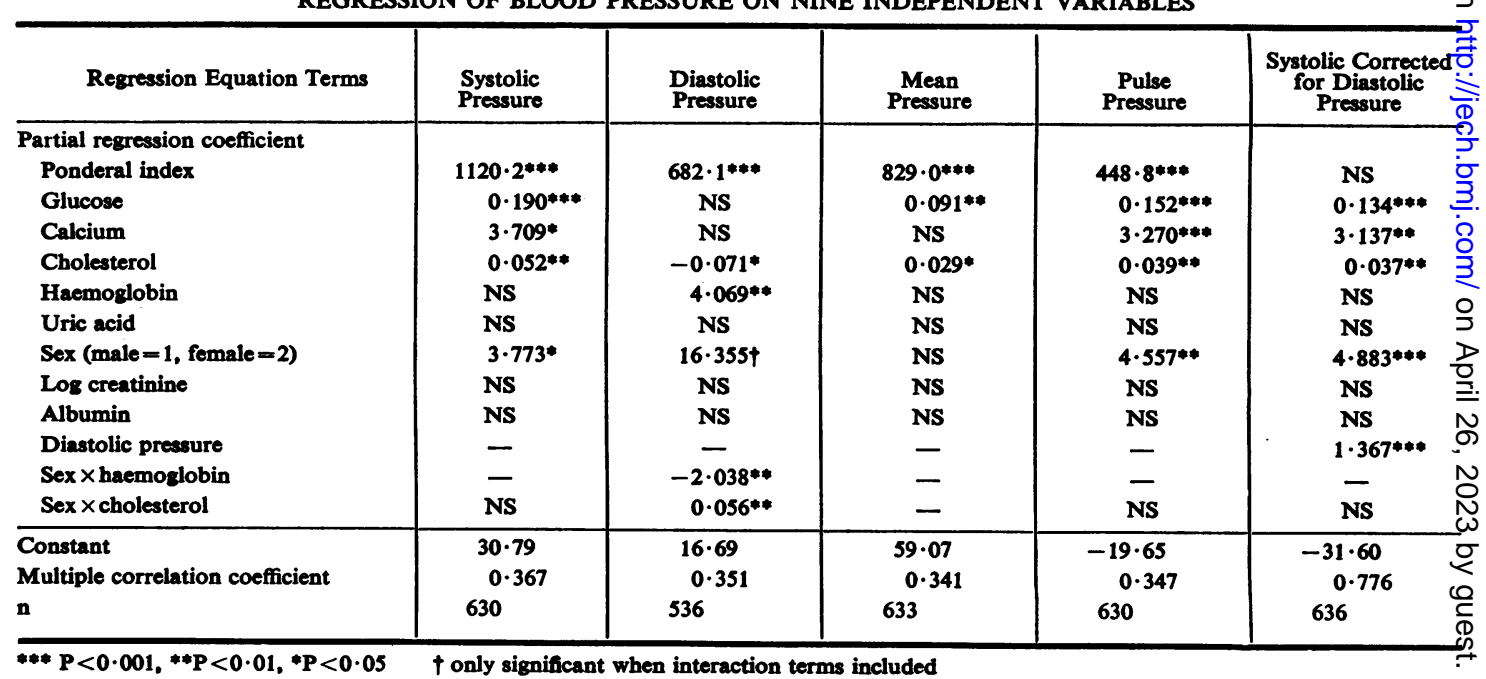


Mean blood pressure was positively related to relative weight, serum glucose, and cholesterol. The equation explained $11.6 \%$ of the variation in mean pressure. Pulse pressure was positively related to relative weight, serum glucose, calcium, cholesterol, and being female. The equation explained $12.0 \%$ of the variation in pulse pressure.

Systolic blood pressure was also regressed on diastolic pressure. The regression coefficient $(1 \cdot 37)$ was significantly different from unity $(P<0.001)$, and therefore the systolic blood pressure, corrected for diastolic blood pressure, was not the same as the pulse pressure. As with pulse pressure, however, the corrected systolic pressure was positively related to serum glucose, calcium, cholesterol, and being female. With the exception of ponderal index, the regression coefficients were also similar in the two equatious. The final equation explained $60.2 \%$ of the variation in systolic pressure.

\section{Discussion}

Serum cholesterol and casual blood sugar are recognized risk factors for cardiovascular disease (Framingham Study, 1973) and the effect of blood glucose is present after allowing for serum cholesterol concentration and the systolic blood pressure (Epstein, 1973). Serum uric acid may also be independently associated with cardiovascular disease (Hall, 1965; Myers et al., 1968), whereas obesity is not an established risk factor (British Medical Journal, 1973).

In the present study, systolic blood pressure in men, but not diastolic pressure, was related to the two established risk factors, glucose and cholesterol, suggesting that systolic pressure (but not diastolic) can be increased by an existing cardiovascular abnormality. Similarly, in women the diastolic pressure was not related to glucose, and the relationship with cholesterol was greater with systolic than diastolic pressure. Atheroma or sclerotic change are capable of reducing aortic and large artery compliance, and the clinical concept that systolic but not diastolic pressure may be raised secondary to an 'ageing' process is therefore supported.

The diastolic blood pressure was positively correlated with haemoglobin in men. This was also found in the Framingham study and the Evans County study (McDonough, Hames, and Garrison, 1965). Possible explanations include the production of erythropoietin by an ischaemic kidney, increased blood volume, and increased blood viscosity. Stamler et al. (1975) also reported that the diastolic pressure was more closely related to haematocrit than the systolic pressure.
The positive association between relative weight and blood pressure has been well documented. It is interesting that the effect of relative weight was similar for systolic and diastolic pressure, but that when systolic pressure was corrected for diastolic pressure the effect was no longer statistically significant ( $t=1.88$ on $620 \mathrm{df})$. This agrees with the study of Sive et al. (1970), who concluded that obesity is only basically associated with an increase in diastolic pressure.

Two studies have failed to find a relationship between cholesterol and blood pressure, the Tecumseh study (Epstein, 1973) and the Glostrup study (Hagerup, 1973), although in both surveys a relationship was found between blood pressure and serum triglyceride concentrations. The Glostrup study examined the mean blood pressure and therefore may have missed a correlation between cholesterol and systolic blood pressure. The Tecumseh study has not yet reported its results in any detail. Pincherle and Robinson (1974) have shown a relationship between cholesterol and both systolic and diastolic pressure in subjects living in the United Kingdom, and Stamler et al. (1975) have reported this association in the United States, but only for White males.

Blood glucose is positively associated with blood pressure (Pyorala, 1972; Stamler et al., 1975), and this is confirmed in this study at least for systolic pressure. Zalokar et al. (1974) and Stamler et al. (1975) found a positive correlation between serum uric acid and both systolic and diastolic blood pressure. The present survey did not reveal a significant association between uric acid and blood pressure for the age group under consideration.

To our knowledge the positive relationship between serum calcium and systolic blood pressure has not been previously reported, and it is of considerable interest in view of the calcification which accompanies atheroma.

In conclusion, systolic blood pressure was related to relative weight, serum glucose, calcium, and cholesterol and it was higher in women. Given the result of these variables, it is possible to compute the difference between the expected and observed systolic pressure for a particular patient. This difference may prove to be a better predictor of subsequent cardiovascular mortality than if the prediction is based solely on the known risk factors. A patient with a systolic pressure inappropriately high for his biochemical risk factors may experience a different pattern of mortality than a patient with an equal but explicable level of pressure. 
The work was supported by a grant from the Department of Health and Social Security. We are indebted to Dr Peter A. Clark for the biochemical analyses, and to Mrs P. A. Love and Mrs M. Wallis for nursing assistance. We also wish to thank all the staff of the group practices where the survey was conducted, and Professor J. N. Morris, Head of Department of Community Health, London School of Hygiene and Tropical Medicine, for his support and advice.

Requests for reprints: C. J. Bulpitt, MD, London School of Hygiene and Tropical Medicine, Department of Medical Statistics and Epidemiology, Keppel Street, London WC1E 7HT.

\section{REFERENCES}

British Medical Journal (1973). Leading article, Obesity and coronary heart disease. Brit. med. J., 1, 566.

EPSTEIN, F. H. (1973). Glucose intolerance and cardiovascular disease. Triangle (En.), 12, 3.

Framingham Study (1973). An Epidemiological Investigation of Cardiovascular Disease, Section 30, edited by W. B. Kannel and T. Gordon. US Government Printing Office, Washington, DC.

HAGERUP, L. M. (1973). Coronary heart disease: risk factors in men and women. Acta med. scand., Supplement 557, 48.

Hall, A. P. (1965). Correlations among hyperuricemia, hypercholesterolemia, coronary disease, and hypertension. Arthr. and Rheum., 8, 846.

HODES, C. (1968a). Screening in general practice. Lancet, 1, 304.

(1968b). The structure and function of a file of patient health data in general practice. J. roy. Coll. gen. Practit., 15, 286.
KANNEL, W. B. and DAWBER, T. R. (1974). Hypertensiono as an ingredient of a cardiovascular risk profile. Brit. J. hosp. Med., 11, 508.

KHosla, T. and LowE, C. R. (1967). Indices of obesity. derived from body weight and height. Brit. J. prev. soc. Med., 21, 122.

McDonough, J., Hames, E. G., and Garrison, G. E.들 (1965). The relationship of haematocrit to cardio- $\overline{\bar{c}}$ vascular states of health in the Negro and White $\widetilde{\widetilde{\Phi}}$ population of Evans County, Georgia. J. chron. Dis.,을 18, 243.

Myers, A. R., Epstein, F. H., Dodge, H. J., and $\vec{\circ}$ MIKKELSEN, W. M. (1968). The relationship of serumuric acid to risk factors in coronary heart disease. Amer. $\vec{\omega}$

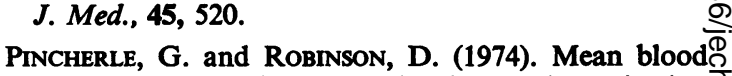
pressure and its relation to other factors determined at a routine executive health examination. J. chron. Dis., 27, 245.

Pyorala, K. (1972). In Symposium on Epidemiology and $\overrightarrow{0}$ Prevention of Coronary Heart Disease, Helsinki, March 1972.

Sive, P. H., Medalie, J. H., Kahn, H. A., Neufeio , $\overrightarrow{\text {, }}$ H. N., and Riss, E. (1970). Correlation of weight-height index with diastolic and with systolic blood pressuge. Brit. J. prev. soc. Med., 24, 201.

Stamler, J., Berkson, D. M., Dyer, A., LepPer, M. h. LiNDBerg, H. A., PAul, O., McKean, H., RHOMberg, P. Schoenberger, J. A., Shekelle, R. B., and Staml R. (1975). Relationship of multiple variables to blo pressure - findings from four Chicago epidemiologic studies. Epidemiology and Control of Hypertension, p. 307. Stratton, New York.

WATSON, D. (1960). A simple method for theō determination of serum cholesterol. Clin. chim. Acta, $5,637$.

Zalokar, J., Lellough, J., Claude, J. R., and Kuntz, Э D. (1974). Epidemiology of serum uric acid and gout in Frenchmen. J. chron. Dis., 27, 59. 